\title{
Addendum
}

\section{Trichlorosilane (HSiCl3) - A Cheap and Convenient Reducing Agent}

Zhiguo Zhang Synlett 2008, 1915.

Two important publications should be included regarding transformation (E): 1) Wang, Z.; Ye, X.; Wei, S.; Zhang, A.; Sun, J. Org. Lett. 2006, 8, 999. 2) Pei, D.; Wang, Z.; Zhang, Y.; Wei, S.; Sun, J. Org. Lett. 2006, 8, 5913. 